\title{
A rapid, non-invasive population assessment technique for marine burrowing macrofauna inhabiting soft sediments
}

Article

Accepted Version

Creative Commons: Attribution-Noncommercial-No Derivative Works 4.0

Campbell, L., Wood, L., Allen Gerwing, A. M., Allen, S., Sizmur, T., Rogers, M., Gray, O., Drewes, M., Juanes, F. and Gerwing, T. G. (2019) A rapid, non-invasive population assessment technique for marine burrowing macrofauna inhabiting soft sediments. Estuarine, Coastal and Shelf Science, 227. 106343. ISSN 0272-7714 doi:

https://doi.org/10.1016/j.ecss.2019.106343 Available at https://centaur.reading.ac.uk/86128/

It is advisable to refer to the publisher's version if you intend to cite from the work. See Guidance on citing.

To link to this article DOI: http://dx.doi.org/10.1016/j.ecss.2019.106343

Publisher: Elsevier

All outputs in CentAUR are protected by Intellectual Property Rights law, including copyright law. Copyright and IPR is retained by the creators or other copyright holders. Terms and conditions for use of this material are defined in the End User Agreement. 


\section{www.reading.ac.uk/centaur}

\section{CentAUR}

Central Archive at the University of Reading

Reading's research outputs online 
A Rapid, Non-invasive Population Assessment Technique for Marine Burrowing Macrofauna

Inhabiting Soft Sediments

4 Lily Campbell $^{1 *}$, Lisa Wood ${ }^{2}$, Alyssa M. Allen Gerwing ${ }^{2}$, Shaun Allen², Tom Sizmur ${ }^{3}$, Megan Rogers ${ }^{4}$,

5 Olivia Gray ${ }^{4}$, Mitch Drewes $^{4}$, Francis Juanes ${ }^{1}$, Travis G. Gerwing, ${ }^{1,2}$

$7 \quad{ }^{1}$ Department of Biology, University of Victoria. Victoria, British Columbia, Canada.

82 Ecosystem Science and Management Program, University of Northern British Columbia. Prince

9 George, British Columbia, Canada.

$10{ }^{3}$ Department of Geography and Environmental Science, University of Reading. Reading, UK.

$11{ }^{4}$ Hidden River Environmental Management. Terrace, British Columbia, Canada.

*Corresponding Author: Lily Campbell. Email: lilyncampbell@ gmail.com

Abstract

Population assessment techniques for soft-sediment infauna (invertebrates within the substrate) requires excavation of specimens, damaging or killing the specimen and surrounding habitat, while being time-consuming and costly. Rapid population assessments of some marine burrowing decapods

20 have been possible by counting burrow openings to estimate abundance, and while they may be used as

21 indicator species, these decapods are not ubiquitous to environments requiring monitoring. Additionally,

22 the presence of other burrowing macrofauna (invertebrates living in the sediment and retained on $1 \mathrm{~mm}$

23 mesh such as clams or large worms) may reduce the efficacy of burrow openings in estimating 
24 macrofauna abundance. As such, we assessed mudflats along the north coast of British Columbia,

25 Canada, during summer 2017 to determine if macrofauna abundances could be estimated from burrow

26 openings on the sediment surface in regions of low $(\mathrm{n}=1$ species $)$ and high $(\mathrm{n}=8$ species $)$ biodiversity.

27 Abundance could not be estimated at the low diversity sites where only one macrofaunal species created

28 burrows. At the high diversity site, species-specific models estimating abundance from burrow openings

29 could not be constructed; however, the total number of burrow openings observed was useful in

30 estimating total infaunal community abundance. As such, burrow openings may not be an effective tool

31 in assessing species-specific abundances, but may be appropriate to estimate overall community

32 changes.

33

34 Keywords: Burrow Openings, Burrowing Organisms Ecological Proxy, Environmental Monitoring, 35 Intertidal Environment, North Coast

36 
Introduction

Understanding the impact of human activity on ecosystem health and biodiversity is a

50 fundamental aspect of applied scientific research (Gonzalez et al. 2016; Vackar et al. 2012). Ecologists

51 and conservation biologists often estimate species abundance, or use population dynamics to achieve a

52 variety of research goals including the assessment of anthropogenic impacts (Cox et al. 2017; Schlacher

53 et al. 2016b; Simao et al. 2006). Although compiling counts of organismal abundance is easy in theory,

54 precise and accurate counts are difficult, and may require invasive techniques (Butler and Bird 2007;

55 Cox et al. 2017; Schlacher et al. 2016b). For example, in marine soft-sediment ecosystems many

56 invertebrates burrow into the substrate (infauna), requiring excavation of individuals from the sediment

57 to assess density and presence/absence. Such methods are destructive to the habitat, and risk stressing,

58 damaging, or killing specimens (Butler and Bird 2007; Schlacher et al. 2016b). In addition to habitat

59 damage, excavations are time consuming, laborious, and costly, limiting the spatiotemporal scale of

60 investigation (Dumbauld et al. 1996; Gilkinson 2008). Therefore, a variety of methods have been

61 proposed for monitoring and estimating infaunal densities, including assessing indicator species or

62 applying ecological indices that can be used as proxies for ecosystem health (Gerwing et al. 2017;

63 Gesteira and Dauvin 2000; Hereward et al. 2017; Schlacher et al. 2016b). Ecological proxies are

64 advantageous as they require less time to assess an area than examining a site holistically, and reduce costs (Butler and Bird 2007; Gilkinson 2008; Schlacher et al. 2016b), although they require pilot studies to evaluate their efficacy (Gerwing et al. 2017; Gerwing et al. 2015b).

In coastal soft-sediment ecosystems that have been degraded by anthropogenic impacts such as

68 urbanization and industrial development (Crain et al. 2008; Gerwing and Cox 2017), fossorial

69 (burrowing) marine decapods have been used extensively as indicator species to detect disturbances 
70 across gradients of human impact. The decapods selected as indicator species have traditionally been

71 ghost crabs (Ocypode sp.) and shrimp from suborder Pleocyemata (Upogebia sp. and Neotrypaea sp.), as

72 they are sensitive to anthropogenic impacts and play key ecological roles (Butler and Bird 2007; Carty

73 2003; D'Andrea and DeWitt 2009; Dumbauld et al. 1996; Hereward et al. 2017; Pillay and Branch 2011;

74 Schlacher et al. 2016a; Stelling-Wood et al. 2016). As both ghost crabs and Pleocyemata shrimp have

75 fossorial habits, researchers have estimated species abundances from statistical relationships between the

76 number of burrow openings and population abundance (Carty 2003; Hereward et al. 2017; Schlacher et

77 al. 2016b). Once the relationship has been determined in a given location, monitoring requires only

78 counting the number of burrows as a proxy for abundance, eliminating the need to excavate pits or count

79 individual specimens (Halpern et al. 2015; Hereward et al. 2017; Schlacher et al. 2016b). However,

80 bivalves and polychaetes also create burrow openings, hence this technique of rapid population

81 assessment may not be limited to fossorial decapods. Although both bivalves and polychaetes have been

82 used as indicator species (Guerra-Garcia and Garcia-Gomez 2004; Hutchins et al. 2009; Pearson and

83 Rosenburg 1978; Talmage and Gobler 2010; Waldbusser et al. 2010; Yunker et al. 2011), relationships

84 between bivalve or polychaete abundance and burrow openings have not been examined as extensively

85 as with decapods. For example, only one study examined relationships between burrow openings and

86 bivalve (Cyrtodaria siliqua) abundances (Gilkinson 2008), while research that quantifies the relationship

87 between polychaete abundance and the abundance of burrow openings is lacking.

Although the majority of research utilizing burrow openings as an ecological proxy has focused

89 on marine fossorial decapods, this group of organisms are not ubiquitous to marine soft-sediment

90 ecosystems. Additionally, it is also possible that the presence of other burrowing macrofauna

91 (invertebrates living in the sediment and retained on a $1 \mathrm{~mm}$ sieve such as clams or large worms) may

92 decrease the efficacy of using burrow openings as proxies for abundance (Butler and Bird 2007; McPhee 
93 and Skilleter 2002). Where only one macrofaunal species is present, monitoring by counting burrow

94 openings may be reliable, but may not be possible when multiple macrofaunal species are present due to

95 the presence of species inhabiting burrows that they didn't create and altering the relationship between

96 the number of burrow openings and abundance (Butler and Bird 2007; McPhee and Skilleter 2002).

97 Conversely, macrofauna often create burrow openings that can be differentiated and identified to species

98 visually, potentially enabling the usage of burrow openings to assess densities outside of monocultures

99 (Harbo 2003; 2007; 2011). For instance, Neotrypaea californiensis (ghost shrimp; Suborder Pleocymata)

100 creates distinctive burrows with a vertical shaft and expelled sediment in a volcano shape around the 101 circular burrow opening (Pillay and Branch 2011) while Abarenicola pacifica (Pacific lugworm) creates

$102 \mathrm{j}$-shaped burrows with rope-like, coiled fecal castings around the burrow opening (Harbo 2003; 2007;

103 2011; Light 2007). Therefore, it may be possible to estimate abundances of these species from their

104 unique burrow openings even in areas of high macrofaunal diversity, and the applicability of burrow

105 openings counts belonging to macrofauna in estimating organismal abundance should be further 106 examined in biodiverse habitats.

107 We assessed intertidal mudflats in British Columbia, Canada, at both low macrofaunal diverse 108 mudflats near Kitimat, and a high macrofaunal diverse mudflat near Prince Rupert in the Skeena 109 Estuary, to determine the efficacy of burrow openings as proxies for abundance of macrofauna. Both 110 Kitimat and Prince Rupert are cities near estuarine systems in northern BC, Canada, and are important 111 regions for environmental monitoring due to their history of industrial development including an 112 aluminum smelter, logging, and a pulp and paper mill. Future development is also likely in these 113 regions, including potential potash export terminals, and oil and liquefied natural gas pipelines, 114 refineries, and export terminals (Carr-Harris et al. 2015; McLaren 2016; Simpson et al. 1998; Yunker et 115 al. 2011). As such, trends identified in these systems may provide valuable insights applicable to other 
116 estuarine systems (Gerwing et al. 2015a; Gerwing et al. 2018b; Hewitt et al. 2016; Little et al. 2017).

117 Therefore, we tested whether a relationship between burrow opening and fossorial organism abundance

118 can be generated in high and low macrofaunal diverse sites, with the goal of creating relationships that

119 could be used to save time and money when assessing macrofaunal populations in the future.

121 Materials and Methods

122 Study Sites

123 Five sheltered intertidal mudflats were sampled for this study: four mudflats with low

124 macrofaunal diversity (i.e. only one macrofaunal species present) in the Kitimat River Estuary and one

125 mudflat with high macrofaunal diversity in the Skeena Estuary (Figure 1). Within the Kitimat Estuary, 126 three mudflats were located within Minette Bay (PL: Pilings; LD: Lodge; LS: Log Sort), while Foxy

127 Beach (FB) was located just outside of Minette Bay. Gerwing et al. (2018a) identified Mya arenaria as 128 the sole macrofaunal species in the Kitimat Estuary, therefore, all burrow openings larger than $0.1 \mathrm{~cm}$ 129 can be attributed to this bivalve.

130 In the Skeena Estuary near Prince Rupert, Wolfe Cove was the only site surveyed, as it was the 131 only mudflat in the area with a diverse macrofauna community. With ghost shrimp (Neotrypaea 132 californiensis), bivalves (Clinocardium nuttallii, Macoma nasuta, M. arenaria) and polychaete worms 133 (Abarenicola pacifica, Nephtys caeca, Alitta brandti, and Glycinde picta) present (Campbell and 134 Gerwing, Unpublished data), Wolfe Cove is a site of high macrofaunal diversity, with multiple species 135 creating relatively large burrow openings $(>0.1 \mathrm{~cm})$ on the substrate surface. 
At each mudflat, five transects were established, stretching from the start of the mudflat to the

139 low tide waterline (60-200 m long, $25 \mathrm{~m}$ apart) (Cox et al. 2017; Gerwing et al. 2015a). Transects were

140 stratified into three equal zones based on distance from shore (near, middle, and far). Within each zone, 141 one sampling location was randomly selected $(n=3$ per transect, 15 per site per sampling period) and a $1421 \mathrm{~m}^{2}$ quadrat was established (Gerwing et al. 2015a). Burrow openings greater than $0.1 \mathrm{~cm}$ were 143 quantified were differentiated based on physical characteristics and classified into three categories as 144 ghost shrimp burrows, lugworm burrows, or other burrow openings. Ghost shrimp burrows were 145 constructed by N. californiensis and identified by the expelled sediment in a volcano shape around the 146 circular burrow opening, characteristic of sheltered mudflats like Wolfe Cove (Pillay and Branch 2011). 147 Lugworm burrows were constructed by A. pacifica, identified by circular burrows with rope-like, coiled 148 fecal castings around the burrow opening (Harbo 2003; 2011; Light and Smith 2007). Other burrow 149 openings were the remaining indistinguishable burrows that were small to medium sized non-descript 150 openings created by bivalves and Nephtyidae or Nereididae polychaetes. After burrow openings were 151 classified, a pit was excavated to quantify the abundance of macrofauna (Cox et al. 2017). Due to 152 differences in availability of resources, a $20 \mathrm{~cm}^{2}$ pit was dug to a depth of $20 \mathrm{~cm}$ at Kitimat mudflats, 153 whereas at Wolfe Cove a $1 \mathrm{~m}^{2}$ pit was dug to a depth of $20 \mathrm{~cm}$ (Cox et al. 2017; Gerwing et al. 2018a). 154 All mud excavated from each pit was sieved through a No. 35 mesh sieve $(0.5 \mathrm{~mm})$ opening. Where 155 possible, macrofauna were identified in the field and immediately released. Specimens that could not be 156 identified in the field were retained and later identified under a dissecting microscope (Light and Smith 157 2007). One mudflat was sampled per day at the lowest low tide during three sampling periods over the 158 summer of 2017 (May 25-31, June 22-28, July 17-24). The LS mudflat was not sampled during the first 159 sampling period, (May 25-31), and PL was not sampled in the last sampling period (July 17-24). This 160 sampling scheme resulted in a total of 30-45 sampling events conducted per mudflat. 
Statistical analysis

Data were analyzed using IBM SPSS software version 24.0. Data were in the form of counts and 164 a large number of zeros were present in the dataset, skewing the dataset significantly to the left. The 165 dataset was deemed non-normal, and therefore a Spearman's rho correlation was used to determine the 166 relationships between each of the species population counts and each burrow type counted. In order to 167 determine if there were significant differences in the relationship between $M$. arenaria and burrow 168 abundance among the four mudflats surveyed at the Kitimat location, a Kruskal-Wallis test was 169 performed.

Following the Spearman's correlation analysis, a Poisson log probability distribution was 171 employed to create general linear models (GLMs) based on significant correlations. This distribution is 172 ideal when analyzing non-normal data in the form of counts (Zuur et al. 2009). Sampled population 173 counts were summed for calculating model statistics based on similarities in statistically significant 174 correlations calculated at Wolfe Cove. Abundance for A. brandti, A. pacifica, and M. arenaria were 175 summed, and G. picta, M. nasuta, and N. californiensis were summed because of their common 176 statistically significant correlation in the same direction (negative and positively respectively) to non177 descript "other burrow openings." The abundance of lugworm burrows and other burrow openings were 178 used as covariates, while sampling date was a fixed factor, to predict the summed population numbers 179 for A. brandti, A. pacifica, and M. arenaria. The abundance of other burrow openings was modelled as a 180 covariate with sampling date a fixed factor to predict the summed population numbers for G. picta, $M$. 181 nasuta, and N. californiensis. Other dependent variables were modeled, including abundance of $N$. 182 caeca, while other covariates and fixed variables were explored in GLMs including transect number and 183 ghost shrimp burrow abundance in order to assess their impact on model significance. Only covariates 
184 and fixed factors with an $\alpha$ less than 0.05 were deemed acceptable for use in the models. Where multiple 185 burrow types were entered as covariates in a model, the interaction effect of these openings was also 186 entered as a model variable; for example, lugworm burrows X other burrow openings. Model residuals 187 were graphed to assess model reliability.

189 Results

190 Kitimat

191 At Kitimat, the low macrofaunal region where only one macrofaunal species (Mya arenaria) was 192 observed, significant relationships were found between the burrow openings and population abundance 193 of $M$. arenaria at three of the four mudflats (rho $=0.458, p<0.001)$. No significant relationship was 194 found at the LS site, and therefore this site was excluded from further analyses. No significant 195 differences in the distribution or median M. arenaria abundance existed between the three mudflats 196 analyzed, so data were grouped for further analyses.

197 Burrow openings were entered as a covariate in a GLM to predict population abundance of $M$. 198 arenaria and were shown to have a significant effect on the model outcome (omnibus test was 199 significant; likelihood ratio Chi-square $=22.48, p<0.001$ ). Given the significance in the GLM, burrow 200 openings were used to assess abundance in a model with a Poisson log distribution; however, when raw 201 model residuals were plotted as a function of predicted values the model showed significant bias and 202 slight heteroscedasticity yielding the model results unreliable (Figure 2). Furthermore, removing one 203 data point made the model insignificant. Therefore, no meaningful model could be derived from the 204 Kitimat data collected. 
At Wolfe Cove, the high diversity mudflat, partial correlations were determined to calculate the 208 similarity in the variation between population and burrow type, conducted while maintaining a constant 209 distance from shore $(\alpha<0.1$ to identify patterns (Beninger et al. 2012)). Although eight macrofaunal 210 species were identified at Wolfe Cove, the abundance of Clinocardium nuttallii did not show a 211 significant relationship to any type of burrow opening (Table 1). The abundance of some species 212 encountered had statistically significant relationships with the number of burrows, but these 213 relationships were not all positive (Table 1). For example, Abarenicola pacifica abundance was 214 positively correlated, while Nephtys caeca abundance was negatively correlated to lugworm burrows. 215 The number of Glycinde picta, Macoma nasuta, and Neotrypaea californiensis individuals were all 216 positively correlated with the abundance of other burrow openings, while Alitta brandti, A. pacifica and 217 M. arenaria population numbers were negatively correlated to other burrow openings and positively 218 correlated with lugworm burrow openings (Table 1). Population counts for species that shared common 219 variability were summed to form the dependent variables of the subsequent general linear models, 220 therefore individual correlations shown in Table 1 are not related to the significance of covariates used 221 in these models.

The following models revealed significant predictive relationships:

Total population abundance of G. picta, M. nasuta, and $N$. californiensis was predicted by other burrow openings (covariate) and the date of sampling (fixed factor) (likelihood ratio Chi-square $=97.892, p<$ 0.001). The linear relationship between the predicted values and the observed population abundance of G. picta, M. nasuta, and N. californiensis is described by the following equation:

$$
Y=0.47+0.75 x\left(r^{2}=0.740 ; \text { Figure } 3\right)
$$

The total population abundance of A. brandti, A. pacifica, and M. arenaria was predicted by the number 229 of lugworm burrows and other burrow openings (covariates) and the date of sampling (fixed factor) 
230 (likelihood ratio Chi-square $=72.462, p<0.001$ ). The linear relationship between the predicted values 231 and the observed total population abundance of these species is described by:

$$
Y=3.8+0.45 x\left(r^{2}=0.421 ; \text { Figure } 4\right)
$$

233 A. pacifica was significantly correlated with ghost shrimp burrows when the independent Spearman's 234 rho values were calculated (Table 1); however, when modeled as total abundance with A. brandti, and 235 M. arenaria, the total abundance of these species can be modeled more appropriately by lugworm and 236 other burrow opening types than ghost shrimp burrows.

237 Lastly, N. caeca was modeled by lugworm burrow and other burrow opening counts (covariates), and 238 date of sampling (fixed factor) (likelihood ratio Chi-square $=26.523, p<0.001$ ). A significant

239 interaction effect was noted between lugworm burrows and other burrow openings in the model of $N$. 240 caeca $(p=0.029)$. The linear relationship between the predicted values and the observed counts of $N$. 241 caeca population abundance is described by the following equation:

$$
\mathrm{Y}=4.42+0.28 \mathrm{x}\left(\mathrm{r}^{2}=0.277 ; \text { Figure } 5\right)
$$

243 Although the Spearman's rho value shows a relationship between N. caeca abundance and combined 244 ghost shrimp burrows and lugworm burrows, when modeled with other variables of consideration (other 245 burrow openings, sampling date, transect) ghost shrimp burrows became insignificant to the model.

247 Discussion

$248 \quad$ Kitimat

The objective of this study was to determine if relationships between the number of burrow 250 openings and the abundance of macrofauna could be modelled at both high and low diversity mudflats 251 on the north coast of British Columbia. At the Kitimat mudflats with only one macrofaunal burrowing 252 species, the positive correlation between burrow openings and the number of Mya arenaria was 
253 statistically significant; however model residuals were unreliable as they were biased with

254 heteroscedasticity resulting in no significant and meaningful model created with the Kitimat data.

255 Therefore, burrow openings were not a good proxy for M. arenaria densities.

256 To the best of our knowledge, the only other study attempting to use burrow opening counts to 257 quantify bivalve abundance used the deep-sea propeller clam Cyrtodaria siliqua and examined the effect 258 of dredging on the relationship between burrow openings and C. siliqua abundance (Gilkinson 2008). 259 Although not all experimental treatments in their study revealed statistically significant relationships, the 260 ones that did showed moderate to strong relationships with clam densities $(\mathrm{r}=0.50-0.72)($ Gilkinson 261 2008). However, their study found a temporal change in the ratio of burrows to bivalve abundance, with 262 a decreasing number of burrows but consistent abundance of $C$. siliqua over multiple years (Gilkinson 263 2008). As temporal variation may be a factor in relationships between burrow openings and macrofauna 264 abundance, more data would be required to see if the temporal scale of this research was too short to 265 detect a temporal trend, and perhaps a stronger relationship and more reliable model could be generated 266 by collecting more data during each sampling period, or sampling all year (Bringloe et al. 2013).

268 Wolfe Cove

At Wolfe Cove, high macrofaunal biodiversity made it more difficult to create a single, 270 meaningful statistically significant relationship between burrow openings and species abundance. Of the 271 eight species encountered, only Clinocardium nuttallii abundance was not significantly correlated with 272 any of the observed burrow types. This was likely due to the low number of $C$. nuttallii encountered, as 273 only a total of seven individuals were found throughout the sampling period. Therefore, more data 274 would be required to properly assess the relationship between $C$. nuttallii abundance and the number of 275 burrow openings. 
The number of burrows identified as belonging to ghost shrimp showed weak correlations to

277 three of the eight species investigated, including between these burrows and Neotrypaea californiensis abundance. While significant, this correlation was expected to be stronger as numerous $N$. californiensis were observed in the sediment at the time of sampling. Furthermore, previous studies have found significant and stronger relationships between the number of burrow openings and abundance of $N$.

281 californiensis (Carty 2003; Dumbauld et al. 1996). While unexpected, both Carty (2003) and Dumbauld 282 et al., (1996) used either a suction or large core rather than digging a pit as was done in this study. The 283 vertical shaft of N. californiensis' burrow can be up to $90 \mathrm{~cm}$ deep (Dumbauld et al. 1996), therefore, 284 excavating a pit to $20 \mathrm{~cm}$ depth may not have been sufficient to capture all specimens present in the $1 \mathrm{~m}^{2}$ 285 quadrat. However, this method was chosen because at this mudflat below $20 \mathrm{~cm}$ depth the sediment 286 particle size became larger and transitioned into gravel, reducing the likelihood that N. californiensis 287 were present below this depth, and eliminating the ability to use suction as an extraction technique. The high number of other burrowing infauna at this site may have also introduced too much variability into the habitat, reducing the ability to create strong relationships between $N$. californiensis abundance and burrow openings (Butler and Bird 2007; McPhee and Skilleter 2002).

Previous research has also noted that burrow opening counts cannot distinguish between uninhabited and inhabited burrow openings, which may have influenced our results, and is one of the reasons burrow opening/population abundance relationships may produce highly variable population estimates (Schlacher et al. 2016b). This is especially a problem for mobile, errant taxa like Thalissinidean shrimp and certain polychaetes (e.g. Nephtyidae or Nereididae), as they can vacate their burrows or burrow through the sediment. Additionally, when excavating pits, mobile Nereididae worms openings as estimators of population abundance may not be appropriate for mobile invertebrates. 
The abundance of the lugworm Abarenicola pacifica was significantly positively correlated to 300 the number of burrows identified as lugworm burrows, although a statistically significant GLM could 301 not be created with just A. pacifica and lugworm burrows. Of interest, Nephtys caeca was also 302 significantly correlated with burrows identified as lugworm burrows, although the correlation was 303 negative. This may be due to the bioturbating activities of lugworms that can influence polychaete 304 assemblages, and their presence can negatively affect abundances of other polychaetes, especially 305 mobile predatory worms (Volkenborn and Reise 2007).

The abundance of Macoma nasuta, N. californiensis and Glycinde picta were all positively correlated to the number of 'other burrow openings' (burrow openings identified as not belonging to ghost shrimp or lugworms), while Alitta brandti, A. pacifica and M. arenaria were negatively correlated to these openings. This result provides major challenges for using burrow openings as estimates of individual species densities, as it eliminates our ability to assign burrow openings to a given species.

313 monitoring population declines.

However, it does allow for the ability to create models which express the relationship between population abundance and the type of burrow opening found (Equations 1-3), with applications for

Of particular interest is the significant effect of sampling date on these models, suggesting that temporal variation is an important consideration for modelling invertebrate abundances from burrow opening counts. Previous research has found temporal variation to be a component of these models for 321 bivalves as previously mentioned, and for Pleocyemata shrimp species (Dumbauld et al. 1996; Gilkinson 2008; Schlacher et al. 2016b). As such, future research should be directed at furthering our knowledge of temporal variation in these relationships, and understanding how to determine the appropriate sampling date or sampling interval. 
Although using burrow opening counts to estimate individual species abundance may not be

324 effective in low diversity sites, burrow counts in high macrofaunal diverse sites may still be a useful tool 325 for monitoring. For instance, in a heavily polluted estuary, simply counting macrofauna burrows without 326 assigning the burrow to a given taxa was sufficient to detect responses of the infaunal community along 327 the gradient of pollution (Saiz-Salinas and Gonzalez-Oreja 1999). Although burrow openings were 328 unable to predict individual infaunal abundances at our high diversity sites, openings were still able to 329 predict overall infaunal abundances, and therefore may be able to detect changes in habitat condition 330 over time in these systems. Burrow opening counts may therefore be an appropriate monitoring method 331 to identify potential infaunal population changes and relate them to alterations in habitat condition.

332 Counting burrow openings would be quicker, cheaper, and less destructive than excavation and 333 identification of infauna to a given taxonomic unit (Gilkinson 2008; Saiz-Salinas and Gonzalez-Oreja 334 1999; Schlacher et al. 2016b). As such, counting burrows could still be a useful monitoring tool when 335 the goal is to detect overall community changes.

\section{Conclusion} model predicting macrofaunal abundance from burrow openings was not possible at low diversity

341 mudflats, while total macrofaunal abundance rather than individual species abundance was predicted at 342 the high diversity mudflat. Based upon our findings we therefore recommend considering these three 343 points for burrow opening counts as a rapid and reliable method for estimating the abundance of 344 macrofaunal organisms: 
345 1. Timing of sampling appears to be relevant to macrofaunal counts and future research should be

346 directed at elucidating temporal variation in relationships between burrow openings and

347 invertebrate abundance.

348 2. At high macrofaunal diverse sites, complex interactions exist and therefore burrow opening 349 counts may be more appropriate for predicting total macrofaunal population abundance.

350 3. Regardless of species found, relationships between burrow openings counts and macrofaunal $351 \quad$ abundance must be empirically tested in the system of interest.

352 Although designing a sampling protocol requires the above considerations, burrow opening counts can

353 be powerful tools for ecosystem monitoring. Monitoring population abundance through burrow opening 354 counts has the ability to detect overall changes in abundances, while being less destructive, quicker, and 355 cheaper than traditional excavation methods.

\section{Acknowledgments}

This project was funded by a Mitacs Elevate postdoctoral fellowship to TGG, an NSERC

359 Discovery award to FJ, and an NSERC CGS M to LC. The participation of TS was made possible due to 360 support from the Royal Geographical Society (with IBG) with an Environment and Sustainability

361 Research Grant. Further funding was provided by the Canadian Government's Fish Habitat Restoration

362 Initiative Program, with additional technical support provided by the Haisla Fisheries Commission, 363 particularly Trevor Amos, Len Bolton, Brenda Bouzanne, Craygan Grant, Mike Jacobs, and Everett 364 Smith. Many thanks are due to Justine and Mark Crawford of Cassiar Cannery, and to Howard and Ruth 365 Mills of Minette Bay Lodge for providing logistical support while in the field, as well as to Aleia Wylie 366 for moral support to see this project to completion. 


\section{References}

Beninger PG, Boldina I, Katsanevakis S. 2012. Strengthening statistical usage in marine ecology. Journal of Experimental Marine Biology and Ecology. 426:97-108.

Bringloe TT, Drolet D, Barbeau MA, Forbes MR, Gerwing TG. 2013. Spatial variation in population structure and its relation to movement and the potential for dispersal in a model intertidal invertebrate. Plos One. 8(7).

Butler S, Bird FL. 2007. Estimating density of intertidal ghost shrimps using counts of burrow openings. Is the method reliable? Hydrobiologia. 589:303-314.

Carr-Harris C, Gottesfeld AS, Moore JW. 2015. Juvenile salmon usage of the Skeena River estuary. Plos One. 10(3).

Carty SE. 2003. Zostera marina and Neotrypaea californiensis as indicators of ecosystem integrity in Grice Bay, British Columbia [thesis]. University of British Columbia. 172p. Accessed from Open Collections UBC Theses and Dissertations.

Cox KD, Black MJ, Filip N, Miller MR, Mohns K, Mortimor J, Freitas TR, Greiter Loerzer R, Gerwing TG, Juanes $\mathrm{F}$ et al. 2017. Community assessment techniques and the implications for rarefaction and extrapolation with hill numbers. Ecology and Evolution. 7(24):11213-11226.

Crain CM, Kroeker K, Halpern BS. 2008. Interactive and cumulative effects of multiple human stressors in marine systems. Ecology Letters. 11(12):1304-1315.

D'Andrea AF, DeWitt TH. 2009. Geochemical ecosystem engineering by the mud shrimp Upogebia pugettensis (Crustacea: Thalassinidae) in Yaquina Bay, Oregon: Density-dependent effects on organic matter remineralization and nutrient cycling. Limnology and Oceanography. 54(6):19111932.

Dumbauld BR, Armstrong DA, Feldman KL. 1996. Life-history characteristics of two sympatric Thalassinidean shrimps, Neotrypaea californiensis and Upogebia pugettensis, with implications for oyster culture. Journal of Crustacean Biology. 16(4):689-708.

Gerwing TG, Campbell L, Allen Gerwing AM, Allen S, Cox K, Rogers M, Gray O, Drewes M, Juanes F. 2018a. Potential impacts of logging on intertidal infaunal communities within the Kitimat River Estuary. Journal of Natural History. 52: 2833-2855.

Gerwing TG, Cox K. 2017. Erosion of trust in government consultation will impede the creation of environmental policy. Marine Policy. 83:126-127.

Gerwing TG, Cox K, Allen Gerwing AM, Carr-Harris CN, Dudas SE, Juanes F. 2017. Depth to the apparent redox potential discontinuity (aRPD) as a parameter of interest in marine benthic habitat models. International Journal of Sediment Research. 32:472-480.

Gerwing TG, Gerwing AMA, Drolet D, Barbeau MA, Hamilton DJ. 2015a. Spatiotemporal variation in biotic and abiotic features of eight intertlidal mudflats in the Upper Bay of Fundy, Canada. Northeastern Naturalist. 22:1-44.

Gerwing TG, Gerwing AMA, Hamilton DJ, Barbeau MA. 2015b. Apparent redox potential discontinuity (aRPD) depth as a relative measure of sediment oxygen content and habitat quality. International Journal of Sediment Research. 30(1):74-80.

Gerwing TG, Gerwing AMA, Macdonald T, Cox K, Juanes F, Dudas SE. 2018b. Assessing the relationship between community dispersion and disturbance in a soft-sediment ecosystem. Marine Ecology-an Evolutionary Perspective. 39(4):9.

Gesteira JLG, Dauvin JC. 2000. Amphipods are good bioindicators of the impact of oil spills on softbottom macrobenthic communities. Marine Pollution Bulletin. 40(11):1017-1027. 
Gilkinson K. 2008. Reliability of abundance estimates of the propellerclam (Cyrtodaria siliqua) derived from their burrow openings: A case study from Banquereau, Eastern Canada. Journal of Shellfish Research. 27(2):289-295.

Gonzalez A, Cardinale BJ, Allington GRH, Byrnes J, Endsley KA, Brown DG, Hooper DU, Isbell F, O'Connor MI, Loreau M. 2016. Estimating local biodiversity change: A critique of papers claiming no net loss of local diversity. Ecology. 97(8):1949-1960.

Guerra-Garcia J, Garcia-Gomez J. 2004. Polychaete assemblages and sediment pollution in a harbour with two opposing entrances. Helgoland Marine Research. 58(3):183-191.

Halpern BS, Frazier M, Potapenko J, Casey KS, Koenig K, Longo C, Lowndes JS, Rockwood RC, Selig ER, Selkoe KA et al. 2015. Spatial and temporal changes in cumulative human impacts on the world's ocean. Nature Communications. 6:7.

Harbo RM. 2003. Pacific reef and shore: A photo guide to northwest marine life. Madeira Park, BC: Harbour Publishing.

Harbo RM. 2007. Shells and shellfish of the Pacific Northwest. Madeira Park, BC: Harbour Publishing.

Harbo RM. 2011. Whelks to whales: Coastal marine life of the Pacific Northwest. 2 ed. Madeira Park, BC: Harbour Publishing.

Hereward HFR, Gentle LK, Ray ND, Sluka RD. 2017. Ghost crab burrow density at Watamu Marine National Park: An indicator of the impact of urbanization and associated disturbance? African Journal of Marine Science. 39(1):129-133.

Hewitt JE, Thrush SF, Ellingsen KE. 2016. The role of time and species identities in spatial patterns of species richness and conservation. Conservation Biology. 30(5):1080-1088.

Hutchins CM, Teasdale PR, Lee SY, Simpson SL. 2009. Influence of sediment metal spiking procedures on copper bioavailability and toxicity in the estuarine bivalve Indoaustriella lamprelli. Environmental Toxicology and Chemistry. 28(9):1885-1892.

Light SF, Smith RI. 2007. The Light and Smith manual: Intertidal invertebrates from Central California to Oregon. Carlton JT, editor. Berkeley, Los Angeles, CA, USA: University of California Press.

Little S, Wood PJ, Elliott M. 2017. Quantifying salinity-induced changes on estuarine benthic fauna: The potential implications of climate change. Estuarine Coastal and Shelf Science. 198:610-625.

McLaren P. 2016. The environmental implications of sediment transport in the waters of Prince Rupert, British Columbia, Canada: A comparison between kinematic and dynamic approaches. Journal of Coastal Research. 32(3):465-482.

McPhee DP, Skilleter GA. 2002. Aspects of the biology of the yabby Trypea australiensis (Dana) (Decapoda: Thalassinidea) and the potential of burrow counts as an indirect measure of population density. Hydrobiologia. 485(1-3):133-141.

Pearson TH, Rosenburg R. 1978. Macrobenthic succession in relation to organic enrichment and pollution of the marine environment. Oceanography and Marine Biology. 16:229-311.

Pillay D, Branch GM. 2011. Bioengineering effects of burrowing Thalassinidean shrimps on marine soft-bottom ecosystems. Oceanography and Marine Biology: An Annual Review. 49:137-191.

Saiz-Salinas JI, Gonzalez-Oreja JA. 1999. Measuring redundancy in data from pollution impact studies. Environmental Management. 24(3):415-420.

Schlacher TA, Lucrezi S, Connolly RM, Peterson CH, Gilby BL, Maslo B, Olds AD, Walker SJ, Leon JX, Huijbers CM et al. 2016a. Human threats to sandy beaches: A meta-analysis of ghost crabs illustrates global anthropogenic impacts. Estuarine Coastal and Shelf Science. 169:56-73.

Schlacher TA, Lucrezi S, Peterson CH, Connolly RM, Olds AD, Althaus F, Hyndes GA, Maslo B, Gilby BL, Leon JX et al. 2016b. Estimating animal populations and body sizes from burrows: Marine ecologists have their heads buried in the sand. Journal of Sea Research. 112:55-64. 
Simao DS, Ramos MF, Soares-Gomes A. 2006. Population structure of Callichirus major (Say 1818) (Crustacea:Thalassinidea) in a sandy beach of Rio de Janeiro State, Southeast Brazil coast. Journal of Coastal Research.1165-1168.

Simpson CD, Harrington CF, Cullen WR. 1998. Polycyclic aromatic hydrocarbon contamination in marine sediments near Kitimat, British Columbia. Environmental Science \& Technology. 32(21):3266-3272.

Stelling-Wood TP, Clark GF, Poore AGB. 2016. Responses of ghost crabs to habitat modification of urban sandy beaches. Marine Environmental Research. 116:32-40.

Talmage SC, Gobler CJ. 2010. Effects of past, present, and future ocean carbon dioxide concentrations on the growth and survival of larval shellfish. Proceedings of the National Academy of Sciences of the United States of America. 107(40):17246-17251.

Vackar D, ten Brink B, Loh J, Baillie JEM, Reyers B. 2012. Review of multispecies indices for monitoring human impacts on biodiversity. Ecological Indicators. 17:58-67.

Volkenborn N, Reise K. 2007. Effects of Arenicola marina on polychaete functional diversity revealed by large-scale experimental lugworm exclusion. Journal of Sea Research. 57(1):78-88.

Waldbusser GG, Bergschneider H, Green MA. 2010. Size-dependent pH effect on calcification in postlarval hard clam Mercenaria spp. Marine Ecology Progress Series. 417:171-182.

Yunker MB, Lachmuth CL, Cretney WJ, Fowler BR, Dangerfield N, White L, Ross PS. 2011. Biota sediment partitioning of aluminium smelter related PAHs and pulp mill related diterpenes by intertidal clams at Kitimat, British Columbia. Marine Environmental Research. 72(3):105-126.

Zuur A, Leno E, Walker N, Saveliev A, Smith G. 2009. GLM and GAM for count data. Mixed effects models and extensions in ecology with R. Springer. p. 209-243. 


\section{Tables and Figures}

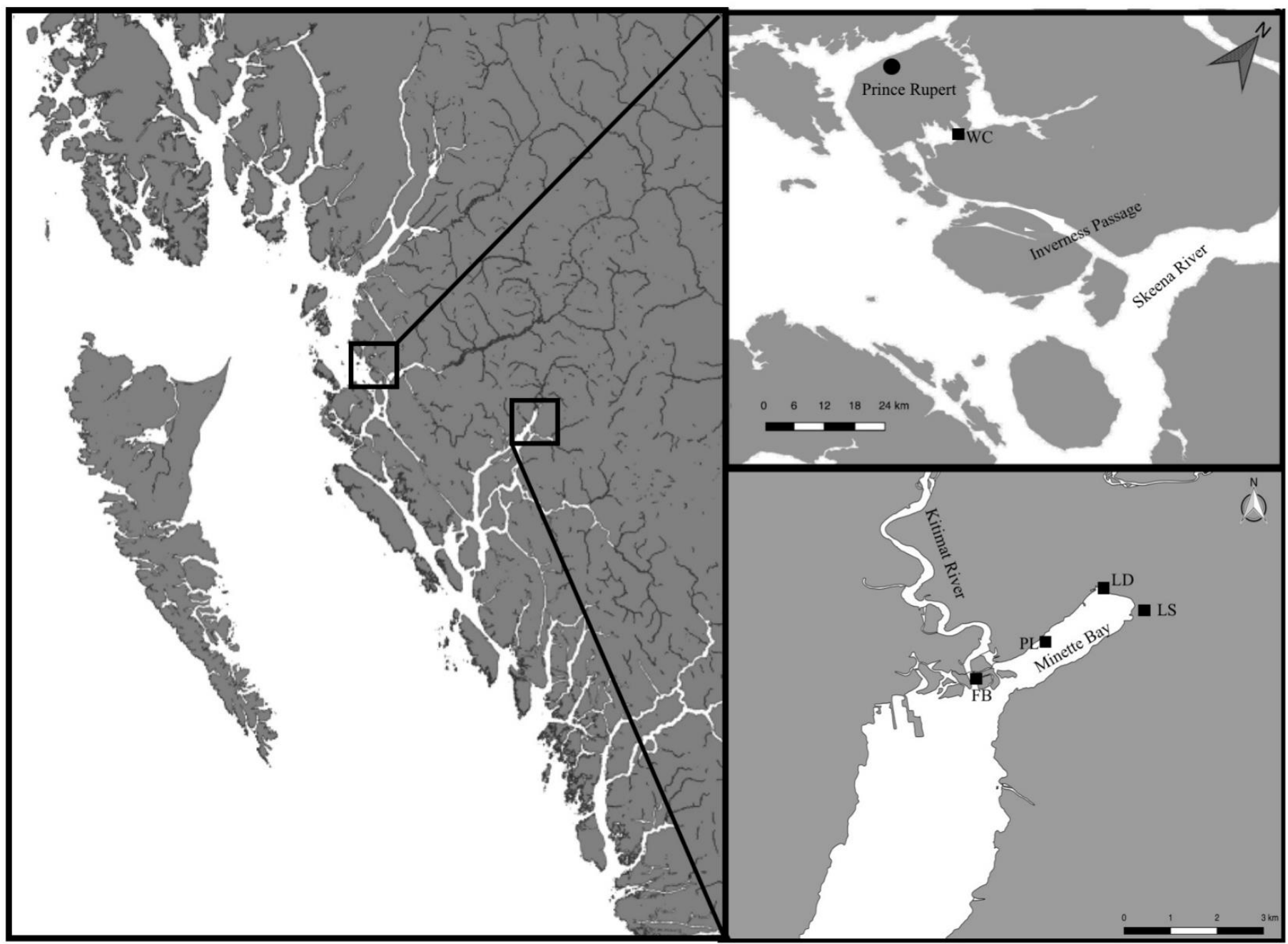

Figure 1. Map of intertidal mudflats sampled during summer 2017 near Kitimat and Prince Rupert, British Columbia, Canada. WC: Wolfe Cove, LS: Log Sort, LD: Log Dump, and FB: Foxy Beach. Mudflat near Prince Rupert in the Skeena River Estuary (WC: Wolfe Cove 54.242433, -130.273033) had high macrofaunal diversity ( $\mathrm{n}=8$ species). Mudflats in the Kitimat River Estuary (LS: Log Sort 54.0248815, -128.610411, LD: Log Dump 54.031088, -128.621355, PL: Pilings 54.015791, 128.632238, and FB: Foxy Beach 54.005785, -128.660710) had low macrofaunal diversity $(\mathrm{n}=1$ species). 


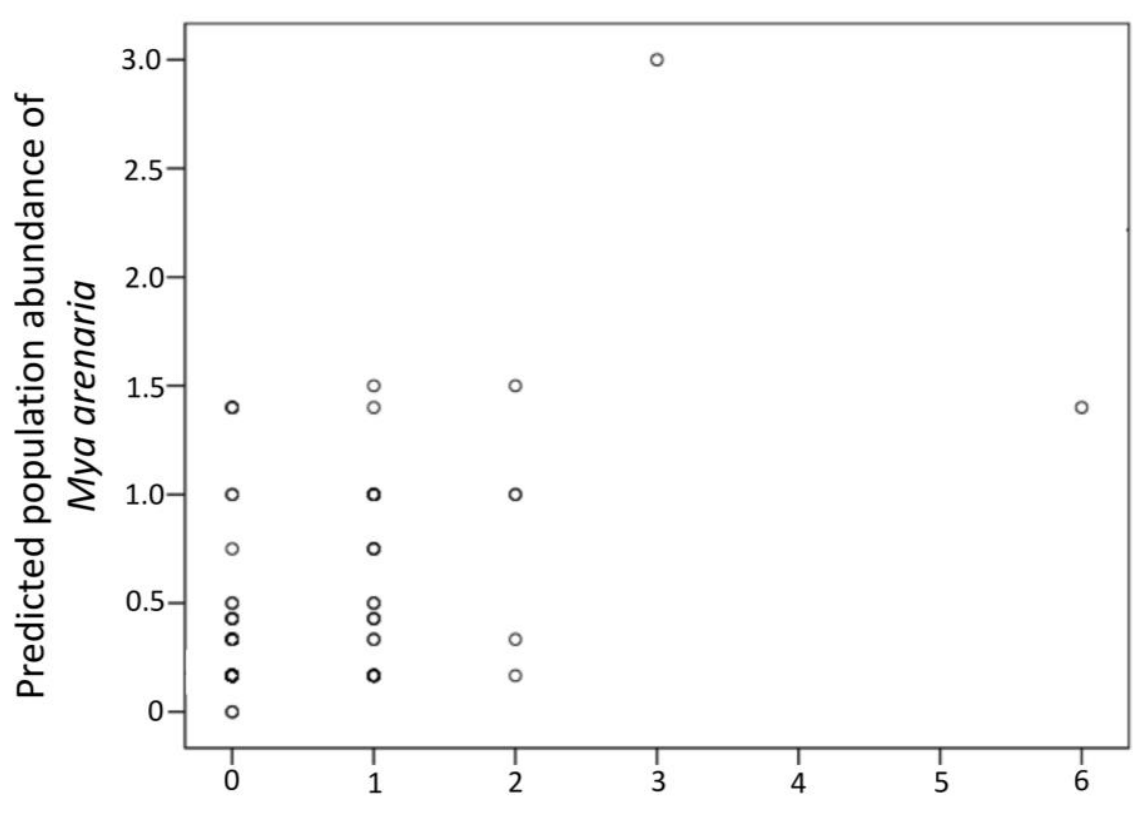

A)

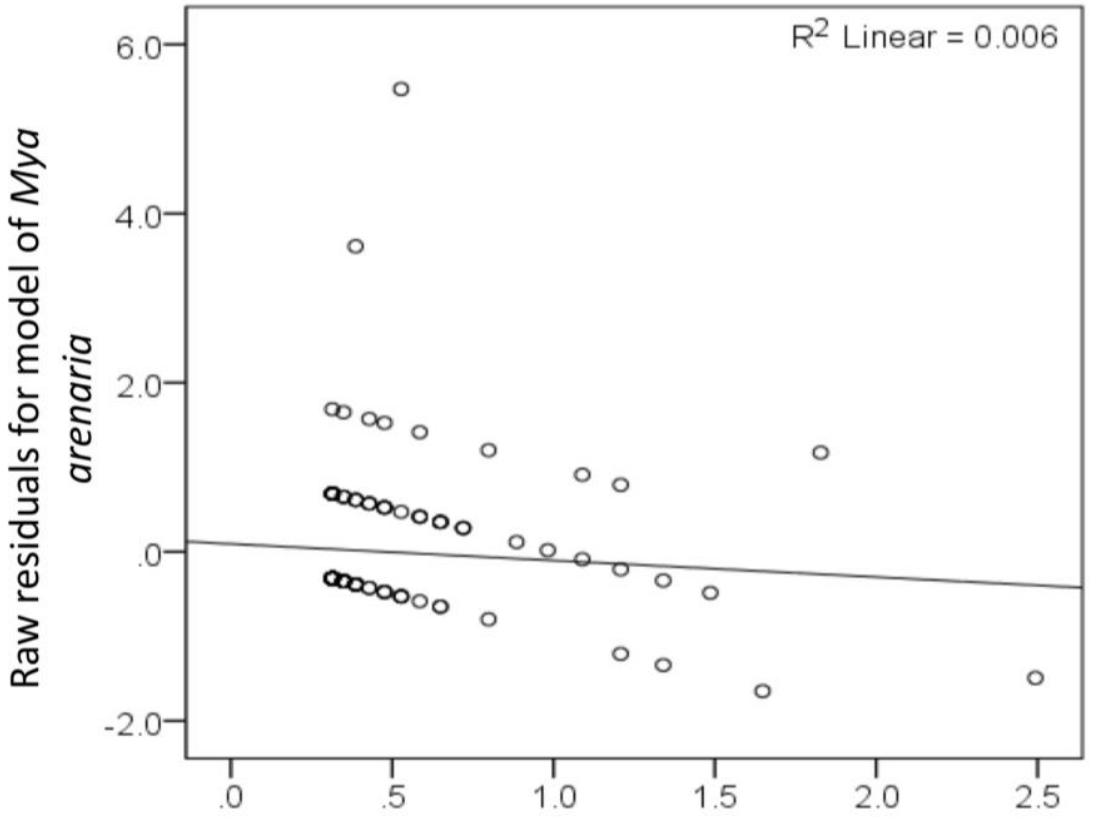

B) Predicted values for Mya arenaria population

Figure 2: Model output for general linearized model of Mya arenaria. A) The relationship between predicted and observed population counts of M. arenaria at Kitimat, BC. Predicted values are based on burrow counts. B) The relationship between model residuals and model predicted values for the linear model created for $M$. arenaria populations based on burrow counts. 


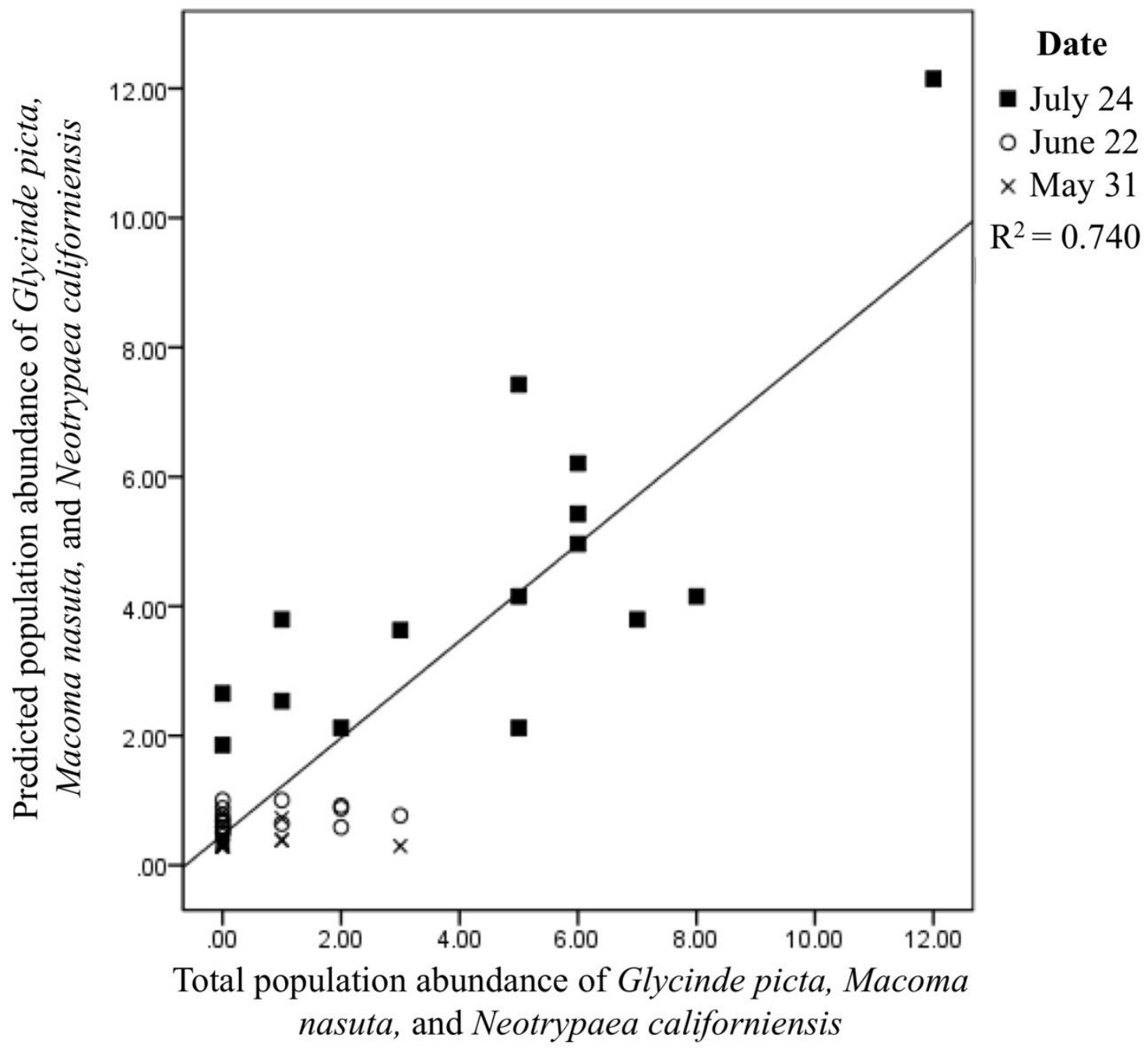

Figure 3. Observed values of Glycinde picta, Macoma nasuta and Neotrypaea californiensis versus predicted values from other burrow openings at Wolfe Cove. Invertebrate populations were counted by excavating and collecting all specimens from a $1 \mathrm{~m}^{2}$ pit to a depth of $20 \mathrm{~cm}$, while burrow openings were counted visually on the surface during low tide in the summer of 2017. 


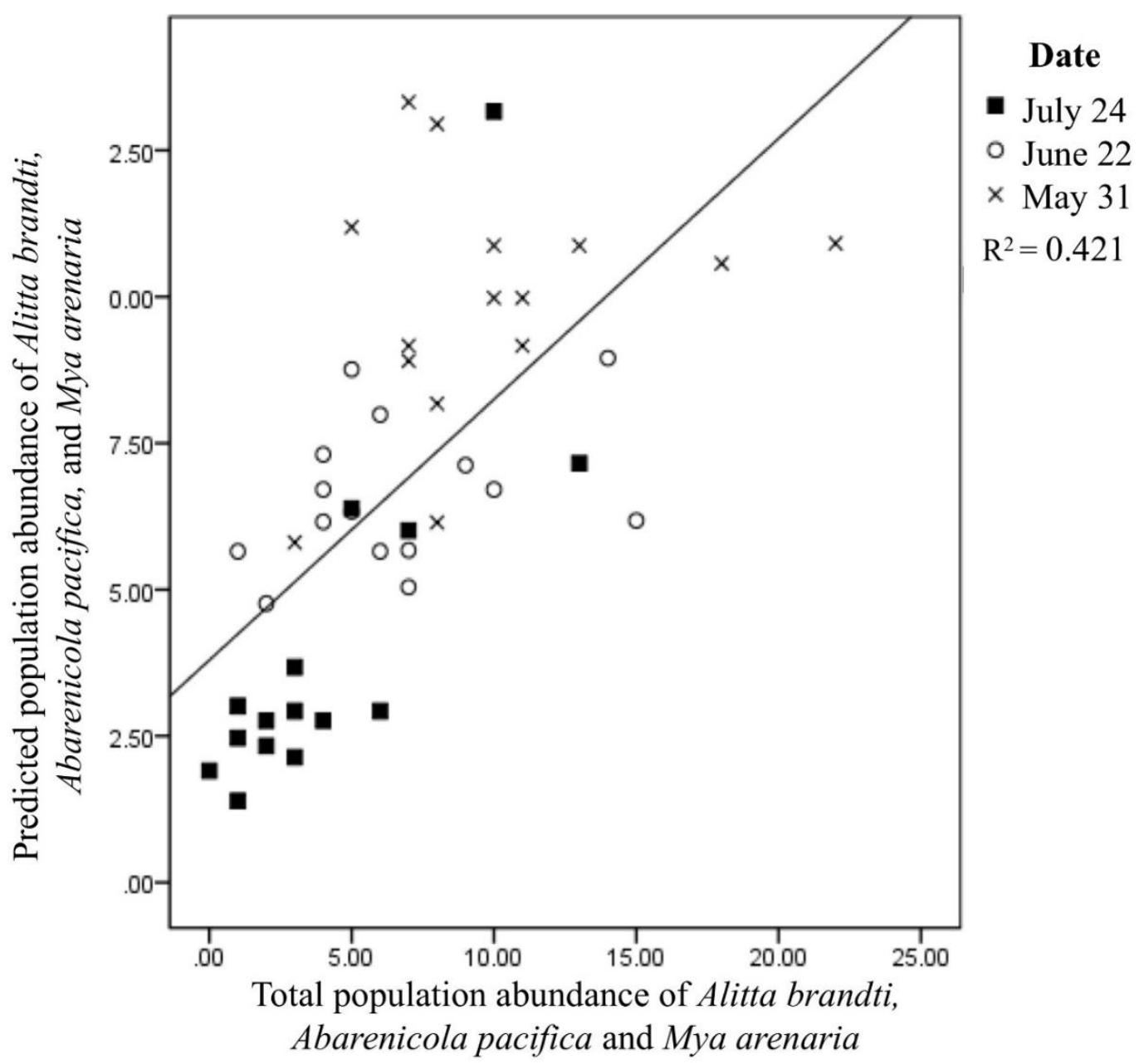

Figure 4. Observed values of Alitta brandti, Abarenicola pacifica, and Mya arenaria populations versus predicted values using lugworm burrows and other burrow openings as predictors at Wolfe Cove. Invertebrate populations were counted by excavating and collecting all specimens from a $1 \mathrm{~m}^{2}$ pit to a depth of $20 \mathrm{~cm}$, while burrow openings were counted visually on the surface during low tide in the summer of 2017. 


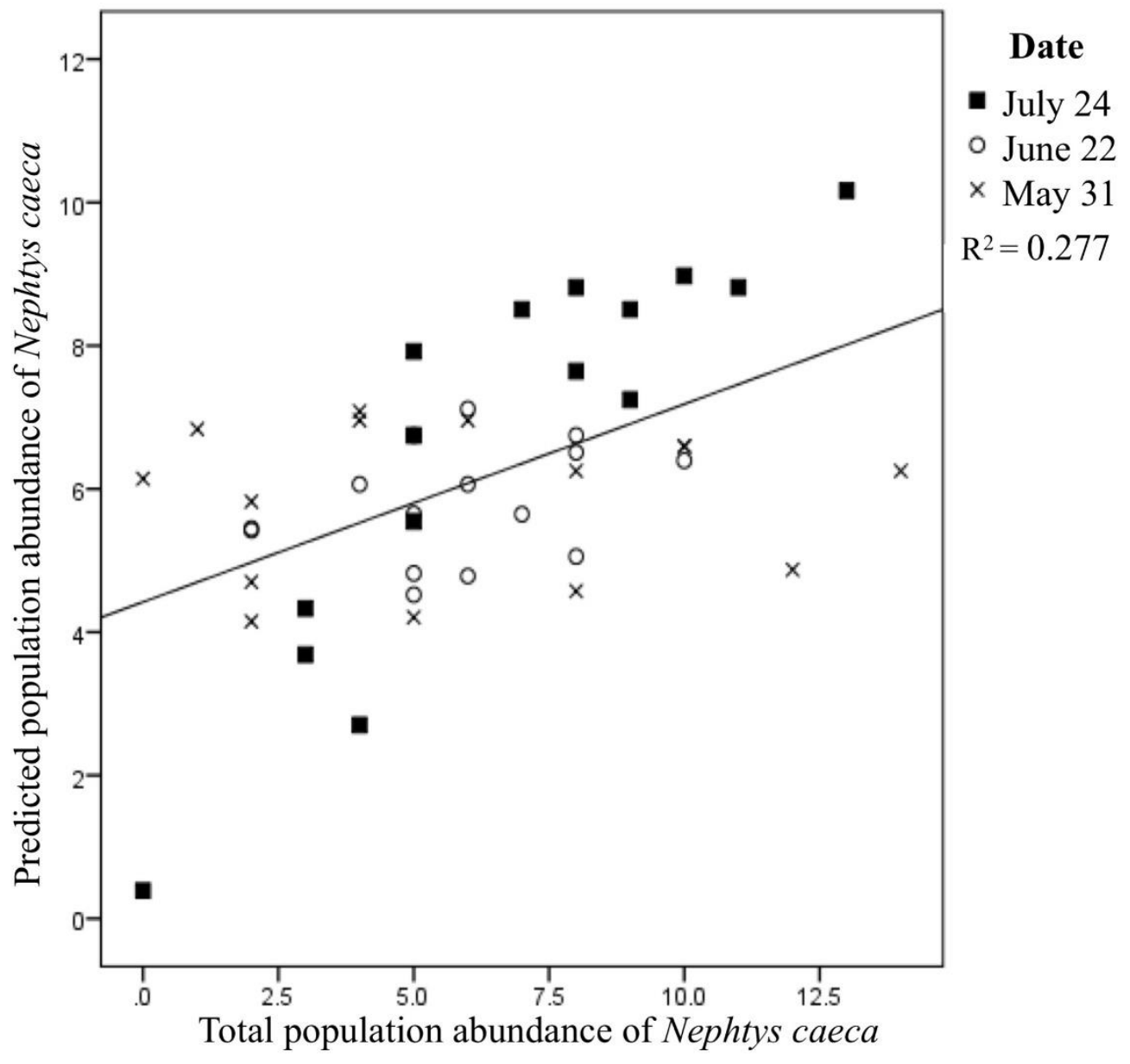

Figure 5. Observed values of the Nephtys caeca population versus predicted abundance using lugworm burrows at Wolfe Cove. $N$. caeca individuals were counted by excavating and collecting all specimens from a $1 \mathrm{~m}^{2}$ pit to a depth of $20 \mathrm{~cm}$, while burrow openings were counted visually on the surface during low tide in the summer of 2017. 
Table 1. Correlation matrix for abundance of macrofauna and type of burrow opening on the substrate surface at Wolfe Cove. Spearman's rho coefficients and associated significance are presented. As we were attempting to identify potential relationships, $\alpha=0.1$ was used to denote significance and statistically significant correlations are shown in bold (Beninger et al. 2012).

\begin{tabular}{|c|c|c|c|c|c|c|c|c|}
\hline & Alitta brandti & Nephtys caeca & Glycinde picta & $\begin{array}{c}\text { Abarenicola } \\
\text { pacifica }\end{array}$ & $\begin{array}{c}\text { Clinocardium } \\
\text { nuttallii }\end{array}$ & Mya arenaria & Macoma nasuta & $\begin{array}{l}\text { Neotrypaea } \\
\text { californiensis }\end{array}$ \\
\hline Other Burrow Openings & $-\mathbf{0 . 3 1 2 , 0 . 0 3 7}$ & $0.227,0.133$ & $0.335,0.025$ & $-0.293,0.051$ & $0.092,0.547$ & $-0.512,0.001$ & $0.508,0.001$ & $0.259,0.086$ \\
\hline Ghost Shrimp Burrows & $-0.111,0.469$ & $0.266,0.077$ & $0.216,0.153$ & $-0.347,0.020$ & $-0.156,0.306$ & $-0.166,0.277$ & $0.071,0.642$ & $0.263,0.081$ \\
\hline Lugworm Burrows & $0.299,0.046$ & $-0.376,0.011$ & $-0.116,0.448$ & $0.501,0.001$ & $-0.083,0.590$ & $0.298,0.047$ & $-0.121,0.427$ & $-0.072,0.641$ \\
\hline
\end{tabular}

